\title{
Numerical simulation of crack propagation behavior of a semi- cylindrical specimen under dynamic loading
}

\author{
Ghorban Khandouzi \\ School of Mining Engineering, College of Engineering, University of Tebran, Tebran, Iran \\ gh.khandouzi@ut.ac.ir \\ Mohsen Mollashahi \\ Department of Mining and Metallurgical Engineering, Amirkabir University of Technology, Tehran, Iran \\ mobsenmollashahi@aut.ac.ir \\ Mojtaba Moosakhani \\ School of Mining Engineering, College of Engineering, University of Tehran, Tehran, Iran \\ mj.moosakhani@gmail.com
}

\begin{abstract}
To design and evaluate the analytical crack propagation of a specimen under dynamic load, measurement of dynamic fracture parameters is necessary. However, analytical methods have significant complexity, and experimental methods are also time-consuming that require high precision and considerable funding. Therefore, numerical methods can be used to solve these problems. The Extended Finite Element Method (X-FEM) as a powerful and efficient tool can be used for this purpose. In this paper, X-FEM code in ABAQUS software was used in order to simulate crack growth in a semi-circular specimen with pre-existed crack and also intact specimen to determine dynamic stress intensity factor (DSIF) using displacement extrapolation method. To verify the numerical modeling output, the curve of crack surface opening displacement (CSOD) in X-FEM model has been compared with the experimental curve. Moreover, concrete damage plastic (CDP) model was used to validate XFEM simulation results. The results show that the DSIF for a cracked sample under a maximum dynamic load $3000 \mathrm{~N}$ is equal to $0.5 \mathrm{MPa} \sqrt{\mathrm{m}}$. Comparison between the CDP and X-FEM results showed that in both approaches, the same area for crack propagation was also determined.
\end{abstract}

KEYWORDs. Extended Finite Element Method (X-FEM); Concrete Damage plastic (CDP); Displacement extrapolation; Dynamic stress intensity factor (DSIF); Crack surface opening displacement (CSOD).

\section{OPEN ACCESS}

Citation: Khandouzi, G., Mollashahi, M., Moosakhani, M., Numerical simulation of crack propagation behavior of a semicylindrical specimen under dynamic loading, Frattura ed Integrità Strutturale, 50 (2019) 29-37.

Received: 10.05 .2019

Accepted: 09.07.2019

Published: 01.10.2019

Copyright: (C) 2019 This is an open access article under the terms of the CC-BY 4.0, which permits unrestricted use, distribution, and reproduction in any medium, provided the original author and source are credited. 


\section{INTRODUCTION}

$\mathrm{I}$ $\mathrm{n}$ most civil or mining projects such as blasting, road tunnels excavation, flying rocks and support systems, the type of the forces applied are dynamic. There are several methods to predict the effect of dynamic loads on structures with a flaw. One of the most important of these methods is introduced by the International Society of Rock Mechanics (ISRM) in 2012. This method uses semicircular specimens with a pre-existing crack under dynamic load.

Measurement of dynamic failure parameters such as stress intensity factor, crack start and crack propagation velocity when analyzing the behavior of a dynamically loaded structure is important. While a dynamic load distribution model increases the level of complexity and the existing analytical solutions are mainly suitable for simple problems, numerical modeling is considered as a suitable tool for solving these problems.

According to Jing [1], a valid numerical model requires complete knowledge of the geometric and physical properties of fractured rock masses. The main challenge is not to build a perfect model, but to create a model that is suitable for the main purpose [1]. For analyzing the fracture, there are a variety of numerical methods for cracking process modeling such as NMM (Numerical Manifold Method) [2], DDA (Discontinuous Deformation Analysis) [3], BEM (Boundary Element Method) [ 4], RFPA (Rock Failure Process Analysis) [5], PFC (Particle Flaw Code) [6], X-FEM [7, 8], and several other in-house codes based on the LEFM Criteria [9]. In addition to creating system equations, two main tasks include evaluating the stress intensity factors (SIF) and fracture growth simulation based on determining the mode of fracture (I, II and III) and different criteria for fracture growth such as maximum tensile strength or energy release rate [1]. So, based on the requirements listed above, as well as Jing expressed in numerical modeling, in this study, XFEM method is used for modeling crack propagation. Failure mechanism consists of two parts start failing and the damage assessment based on the maximum principal stress fracture and power-law fracture criteria. The displacement extrapolation method has been used to determine initiation stress intensity factor and CSOD plot for modeling verification. CDP model is adapted to estimate the failure area in the specimen and comparison between kinetic energy and internal energy for verification of the CDP model.

\section{EXTENDED FINITE ELEMENT METHOD}

$\mathrm{M}$ odeling of fixed discontinuities, such as cracks, using the conventional finite element method, requires that the mesh is compatible with geometric discontinuities. Therefore, a high mesh density is required in the neighborhood of the crack edge to capture the singular asymptotic fields properly. Moreover, modeling of a growing crack is even more complex as the mesh ought to be updated continuously to fit the geometry of the fracture as the crack progresses [10].

The extended finite element method (XFEM) reduces the problems associated with the meshing of crack surfaces [10]. Nowadays, the X-FEM has developed as a powerful numerical method for the analysis of crack propagation [11]. This method mixed finite element and meshless method. Modeling of crack explicitly in this method isn't by the mesh, but it uses the crack geometry implicit description, compatible with any crack path, regardless of its prior condition [12-13]. One of the major benefits of X-FEM on Finite Element Method is the flexibility and versatility in modeling, which does not need to be aligned with the element edges. This method is based on the enrichment of the FE model with additional degrees of freedom (DOF) connected with the nodes of the elements intersected to the discontinuity [14].

\section{Failure criterion in X-FEM}

$\mathrm{X}$-FEM model uses the maximum principal stress criterion for the damage initiation criterion and also a power-law criterion for calculation of damage assessment law. Eqn. (1) illustrates the maximum principal stress criterion:

$$
f=\left\{\frac{\sigma_{\text {Max }}}{\sigma_{\text {Max }}^{0}}\right\}
$$

Where $\sigma_{\text {Max }}^{0}$ shows the maximum principal stress allowed. The Macaulay bracket with the ordinary interpretation is represented by the symbol \langle\rangle . To signify compressive stress that does not initiate damage the Macaulay brackets are used. Initiation of damage is assumed to begin when the maximum stress ratio is equal to one [10].

The Abaqus uses the power - law model described in Eqn. (2): 


$$
\frac{G_{\text {equiv }}}{G_{\text {equiv } C}}=\left(\frac{G_{I}}{G_{I C}}\right)^{\alpha_{m}}+\left(\frac{G_{I I}}{G_{I I C}}\right)^{\alpha_{n}}+\left(\frac{G_{I I I}}{G_{I I I C}}\right)^{\alpha_{0}}
$$

For defining Power-law model or equation, $\mathrm{G}_{\mathrm{IC}}, \mathrm{G}_{\mathrm{IIC}}, \mathrm{G}_{\mathrm{IIIC}}, \alpha_{\mathrm{m}}, \alpha_{\mathrm{n}}$ and $\alpha_{0}$ must be provided; Power-law criterion is described in Wu and Reuter (1965) by Eqn. (2) [10], this equation is very practical in fracture problem and has been applied by Elder et al (2004), Zou (2002) and Lammerant \& Verpoest (1996) [15].

\section{SPECIMEN MODELED IN ABAQUS SOFTWARE}

1

he ISRM has proposed two standard methods for determining static fracture toughness in rocks. They suggest that core-based prototypes experiments be performed on a typical laboratory compression or tension load frame [16]. these proposed specimens are used by Iqbal and Mohanty in the experimental calibration [17]. They contend that the deviation between different results stems from the specimen size, the rock anisotropy, and the dimensionless parameter in the equation of fracture toughness calculation in the CCNBD test [17]. Another method has been introduced by Kuruppu and et.al in 2013 using the same semi-circular bend specimen that introduced by Zhao and et.al (2012) to determine the rock dynamic fracture toughness [18]. The benefits of semi-circular sample (SCB) instead of CB (Chevron Bend), SR (Short Rod) \& CCNBD (Crack Chevron Notched Brazilian Disc) in determining of static fracture toughness are the low requirement of material per each specimen (for meeting the requirements in linear elastic fracture mechanics (LEFM)), simple test setup, and the synchronization of the maximum compressive load with initiation cracking[16]. In some of the cases such as blasting, support system design, explosives storage and rock bursts under dynamic load in seismic events, the dynamic parameters instead of static parameters need to be determined. Furthermore, Zhao et.al has proposed a method to determine dynamic stress intensity factor using semi-circular bending specimen with a straight notch as geometry specimen shown in (Fig. 1).

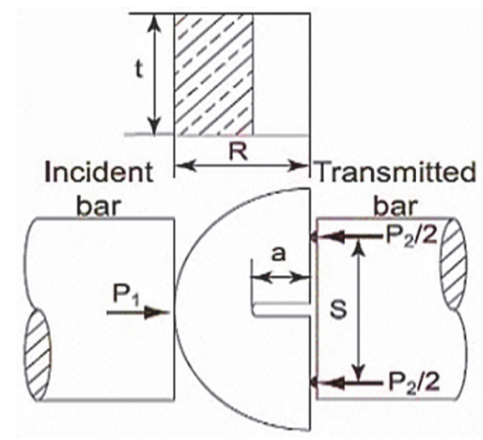

Figure 1: The SCB specimen [18]
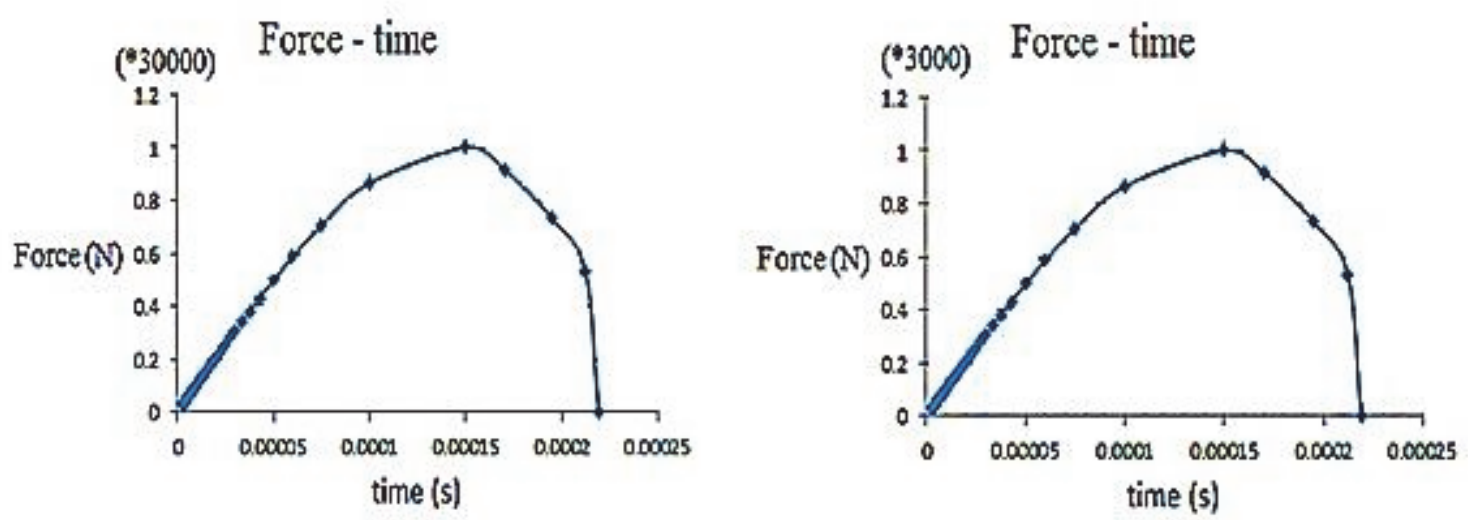

Figure 2: Loads applied to the specimen (30000 left and 3000 right).

Mechanical and geometrical characterizations of specimen simulation using X-FEM are presented in Tab. 1 which has resulted from various laboratory tests.

In this paper, the rock materials are considered isotropic, homogeneous, and elastic. The maximum principal stress failure criterion is selected for damage initiation and an energy-based damage evolution law based on a power-law 
fracture criterion is chosen for damage propagation. These criteria have been described in the previous section. The relevant material data are presented in Tab. 1 resulted from various laboratory tests.

The impact loads applied to the specimen are shown in (Fig. 2).

\begin{tabular}{cc}
\hline SCB specimen & $\begin{array}{c}\text { Mechanical \& } \\
\text { geometry } \\
\text { characterization }\end{array}$ \\
Diameter & $40 \mathrm{~mm}$ \\
2 & 4 \\
Thickness & $20 \mathrm{~mm}$ \\
Distance between & $24 \mathrm{~mm}$ \\
two supports & $7 \mathrm{~mm}$ \\
Notch length & $2400 \mathrm{~kg} / \mathrm{m}^{3}$ \\
Density & $3137 \mathrm{E} 7 \mathrm{~N} / \mathrm{m}^{2}$ \\
Elastic modulus & 0.19 \\
Poison ratio & $10(\mathrm{MPa})$ \\
$\sigma_{\mathrm{Max}}$ & $42200(\mathrm{~N} / \mathrm{M})$ \\
$\mathrm{G}_{\mathrm{Ic}}$ & $42200(\mathrm{~N} / \mathrm{M})$ \\
$\mathrm{G}_{\mathrm{IIC}}$ & $42200(\mathrm{~N} / \mathrm{M})$ \\
$\mathrm{G}_{\mathrm{IIIC}}$ & 1 \\
$\alpha_{\mathrm{m}}$ & 1 \\
$\alpha_{\mathrm{n}}$ & 1 \\
$\alpha_{0}$ & 1
\end{tabular}

Table 1: Mechanical and geometrically characterization of the SCB specimen

The loads applied on numerical samples are the same as the experimental load shape that measured in split Hopkinson pressure bar test. This setup had been used to measure dynamic load by Chen et al (2009) [19], Dai et al (2010) [20] and Dai et al (2011) [21].

\section{MEASUREMENT DYNAMIC STRESS INTENSITY FACTOR AND CRACK SURFACE OPENING DISPLACEMENT (CSOD)}

$\mathrm{D}$ isplacement extrapolation technique has been used for calculation of the intensity of dynamic initiation stress, as shown in Eqn. (3).

$$
k_{I}=\mu \times \sqrt{2 \pi / r} \times \frac{u_{y}^{b}-u_{y}^{a}}{k+1}
$$

Where $\mathrm{k}_{\mathrm{I}}$ is the factor of stress intensity, $\mu$ represents shear modules, $r$ defines the distance from the crack tip, $\mathrm{u}_{\mathrm{y}}^{\mathrm{b}}$ and $\mathrm{u}_{\mathrm{y}}^{\mathrm{a}}$ show displacements at $\mathrm{y}$-direction in the points marked on the model and $\mathrm{k}=(3-\vartheta) /(1+\vartheta)$ is used for plane stress and $\mathrm{k}=3-4 \vartheta$ for plane strain, and $\vartheta$ shows the poison ratio.

According to this method, points positioned in the model, which is shown in (Fig. 3), are used to calculate the dynamic stress intensity factor.

The displacement curve in one direction at four points to determine the stress intensity factor of the crack start is shown in Fig. (6). However, before the crack reaches to horizontal directions of above-mentioned points shown in (Fig. 4), displacement has linear form due to elastic deformation of the specimen while when the crack reaches these points, displacement curve turns into non-linear form. The final result for this strategy is presented in (Fig. 6). 
Moreover, the crack path after the simulation is shown in (Fig. 4). Stress intensity factor according to (Fig. 5) is also presented in Eqn. (4).

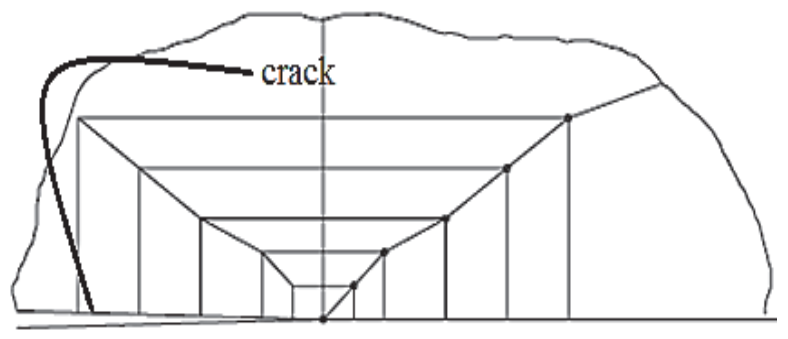

Figure 3: Using displacement extrapolation in order to define stress intensity factor [22].

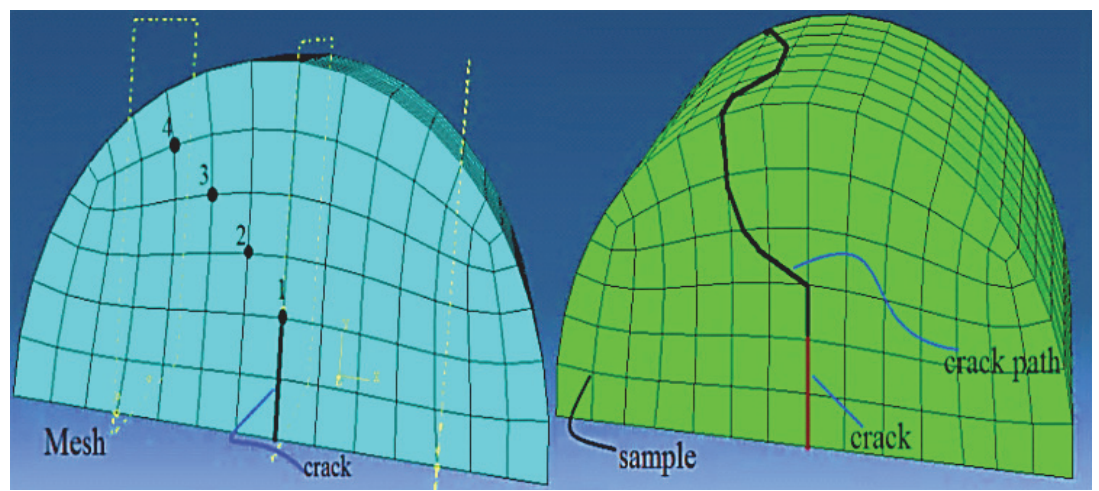

Figure 4: Points and direction for displacement extrapolation method and crack path simulation.

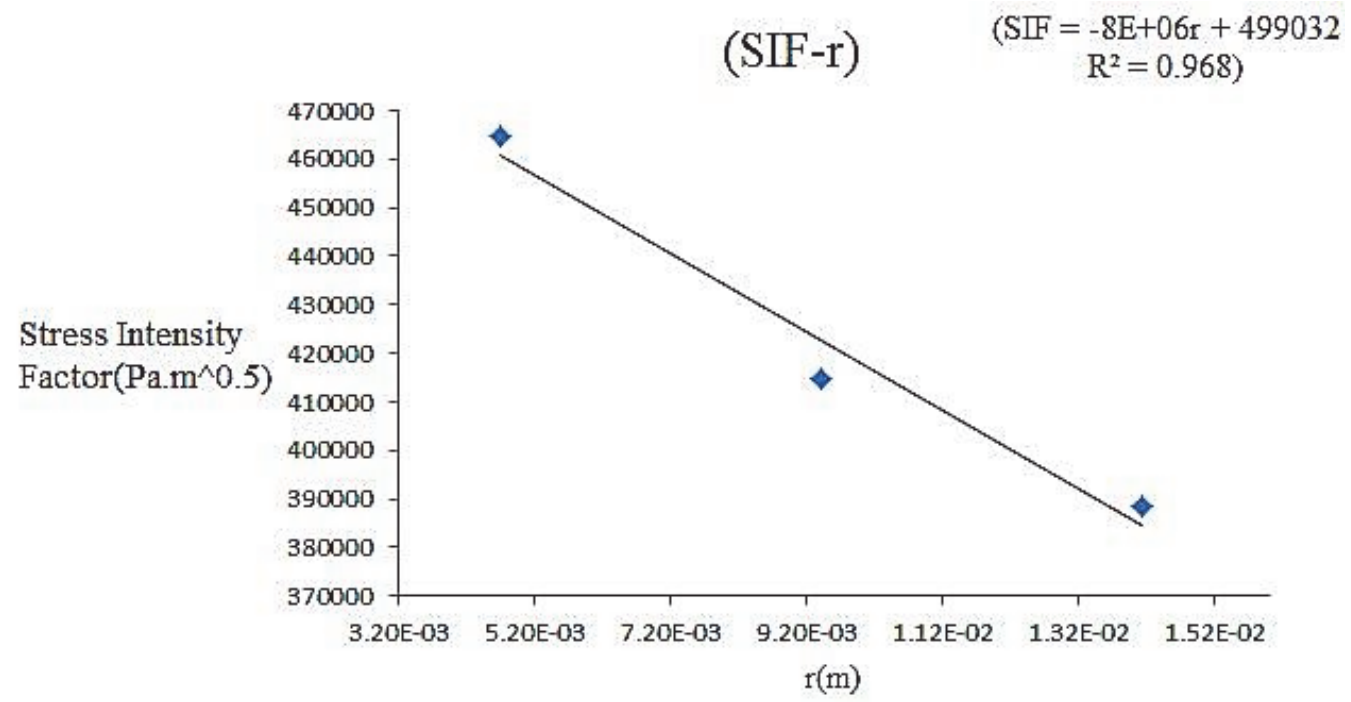

Figure 5: Stress intensity factor according to displacement extrapolation.

if $y \rightarrow K_{I} \& x \rightarrow r$

$$
r \rightarrow 0 \vdots K_{I d}=-8 * 10^{6} *(0)+499032 \rightarrow K_{I d}=0.5 \mathrm{Mpa} \sqrt{m} .
$$

To verify numerical simulation in this paper, experimental data, CSOD graph, as shown in (Fig. 7), is obtained and compared with experimental results measured by Chen et al (2009) [19], Dai et al (2010) [20] and Dai et al (2011) [21]. There is a good agreement between curves' trends of numerical and experimental results. Also, the crack path and crack initiation angle in the X-FEM code is compared and verified with the experimental results of Kalthoff and Winkle (1987) and John and Shah (1990) [10]. 

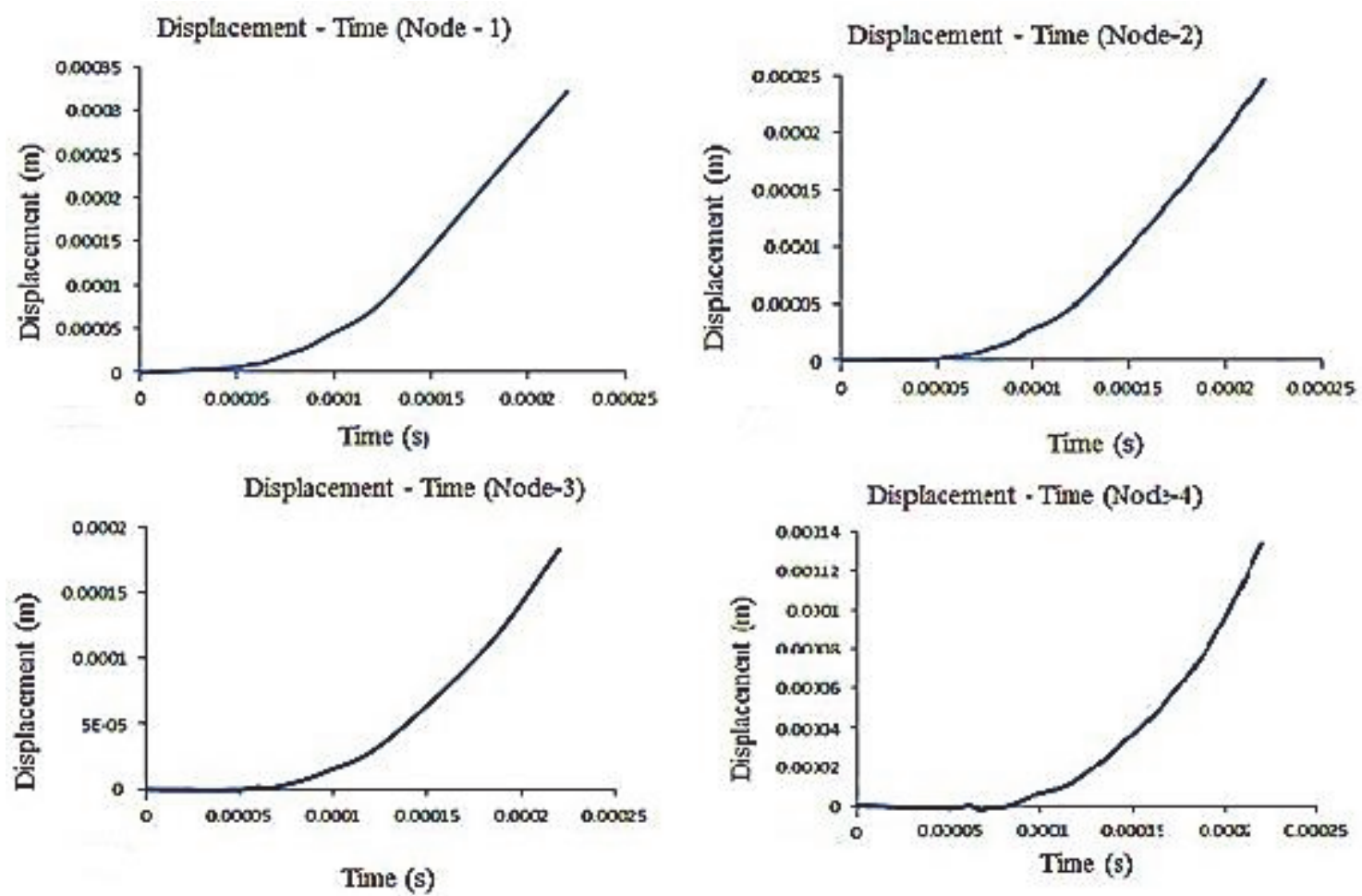

Figure 6: Displacement - time curve for four points on Fig. 6.
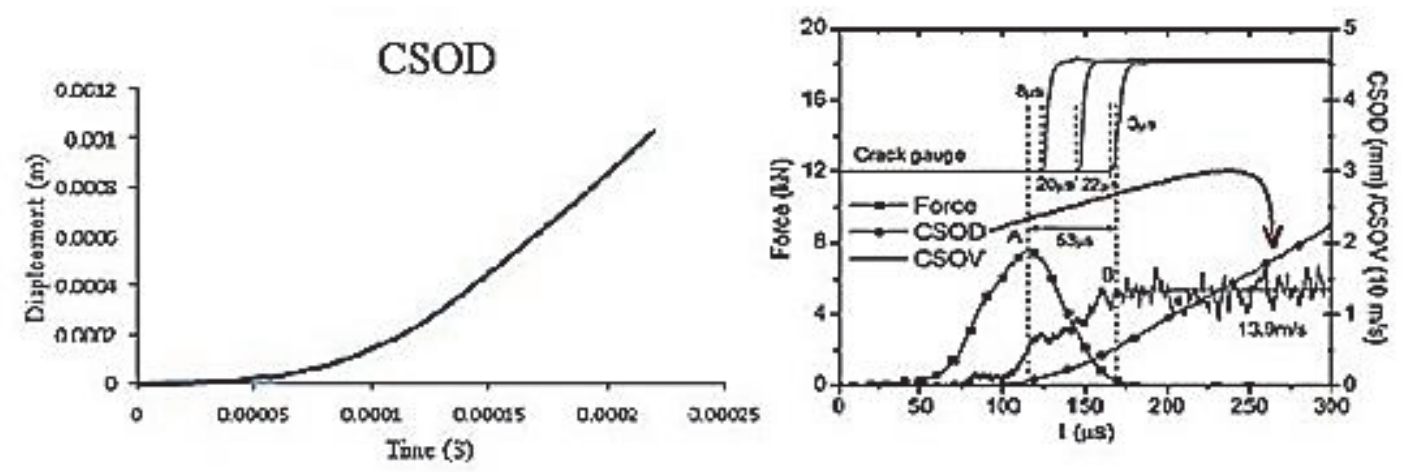

Figure 7: CSOD curve for SCB specimen in X-FEM model [19].

\section{COMPARISONS BETWEEN DAMAGE AND X-FEM METHOD}

$\mathrm{T}$ he concrete damage plasticity (CDP) model herein has just been used to validate X-FEM simulation results. (Fig. 8) illustrates internal energy and kinetic energy for SCB specimen in the CDP model. These curves are used for verification of CDP numerical modeling. According to the CDP model, internal energy has to be 8-10 times of the kinetic energy. In (Fig. 8) internal energy fluctuates between 0 and $1.6(\mathrm{Kj})$ and kinetic energy varies between $0-0.2(\mathrm{Kj})$. According to these results, the internal energy is 8 times kinetic energy.

As it can be seen in (Fig. 9-b), the area with red colour is considered as the crushed area in the CDP model. The same load of $30000 \mathrm{~N}$ used in the X-FEM model (Fig. 9-a). The green area is regarded as a crack propagation area under the same load in X-FEM code. Comparison of two figures show the same areas of crack propagation under the dynamic load.

Dynamic loads of $3000 \mathrm{~N}$ and $30000 \mathrm{~N}$ have been exerted to the models as shown in (Fig. 10-a) and (Fig. 10-b), respectively. Under the dynamic load of $3000 \mathrm{~N}$ the specimen doesn't fail completely (Fig. 10-a) while under the load of $30000 \mathrm{~N}$ the specimen completely failed (Fig. 10-b). Increasing in the load that needs for the propagation of a crack in intact specimen rather than the specimen with initial crack is due to the existence of initial flaw. 

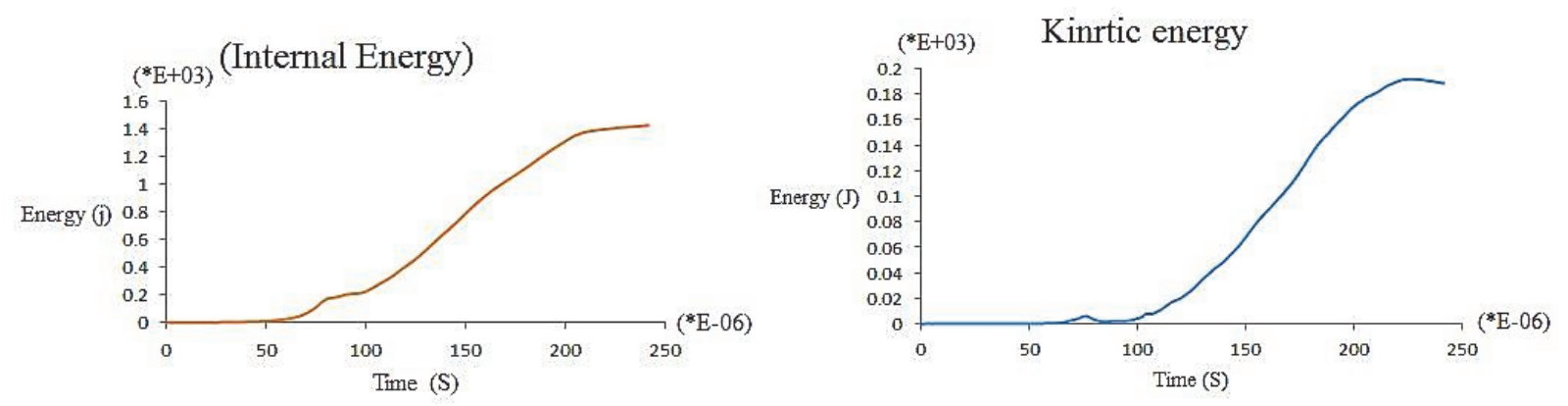

Figure 8: Internal energy and kinetic energy for SCB specimen
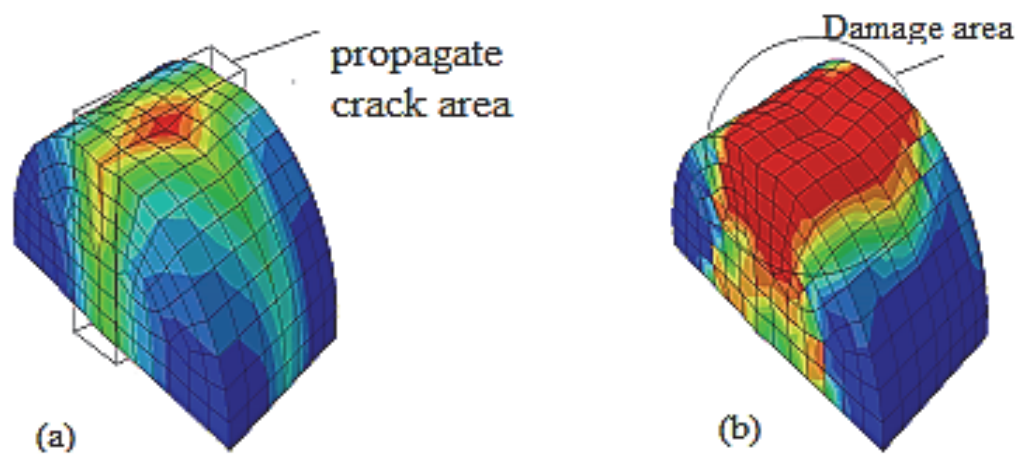

Figure 9: Damage model for SCB specimen-(a) X-FEM \& (b) CDP model
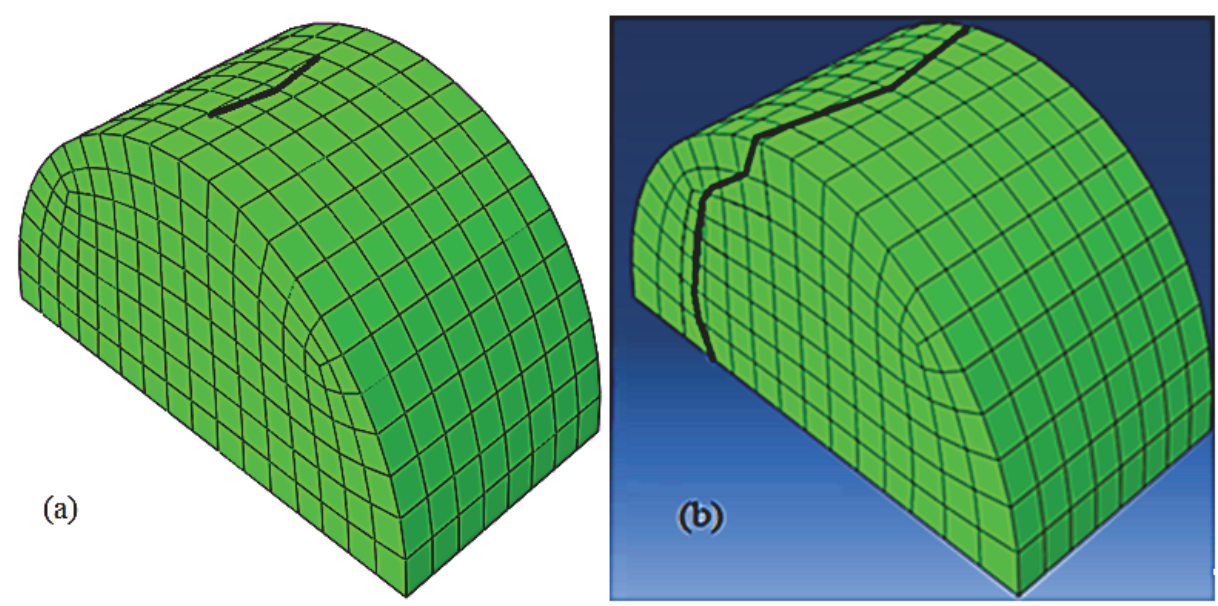

Figure 10: SCB specimen without crack under 3000 N (a) \& 30000 N(b)

Comparison between CDP and X-FEM results (green area in (Fig. 8-a) and (Fig. 10-b)) showed the same area for crack propagation. Therefore, the numerical method is a practical \& powerful method for solving dynamic failure problems.

\section{CONCLUSIONS}

- The cracked semicircular specimen completely failed under the dynamic load of $3000 \mathrm{~N}$ whilst, for intact specimen, it failed under the dynamic load of $30000 \mathrm{~N}$. consequently, It illustrate that existence of any flaw in specimens will decrease the dynamic load required for crack propagation.

- Before the crack was initiated, Displacement - time curve is linear, while it becomes nonlinear when the crack starts to grow. 
- The dynamic stress intensity factor required for crack initiation was calculated by the displacement extrapolation method. According to the obtained results, the DSIF equals $0.5 \mathrm{Mpa} \sqrt{\mathrm{m}}$.

- Comparison between damage and X-FEM models results presents the same area for crack propagation.

- CSOD curve for X-FEM code shows good agreement with experimental test.

- According to the CDP model, the internal energy must to be 8-10 times of kinetic energy. The results demonstrate that internal energy is 8 times of kinetic energy.

- The numerical method is a practical \& powerful method for solving dynamic failure problems.

\section{REFERENCES}

[1] Jing, L. (2003). A Review of Techniques, Advances and Outstanding Issues in Numerical Modelling for Rock Mechanics and Rock Engineering, International Journal of Rock Mechanics and Mining Sciences, 40(3), pp. 283353. DOI:10.1016/s1365-1609(03)00013-3.

[2] Zhang, H.H., Li, L.X., An, X.M. and Ma, G.W. (2010). Numerical Analysis of 2-D Crack Propagation Problems Using the Numerical Manifold Method, Engineering Analysis with Boundary Elements, 34(1), pp. 41-50. DOI:10.1016/j.enganabound.2009.07.006.

[3] Pearce, C.J., Thavalingam, A., Liao, Z. and Bićanić, N. (2000). Computational Aspects of the Discontinuous Deformation Analysis Framework for Modelling Concrete Fracture, Engineering Fracture Mechanics, 65(2), pp. 283-298. DOI:10.1016/s0013-7944(99)00121-6.

[4] Chen, C.-S., Pan, E. and Amadei, B. (1998). Fracture Mechanics Analysis of Cracked Discs of Anisotropic Rock Using the Boundary Element Method, International Journal of Rock Mechanics and Mining Sciences, 35(2), pp. 195-218. DOI:10.1016/s0148-9062(97)00330-6.

[5] Tang, C. (1997). Numerical Simulation of Progressive Rock Failure and Associated Seismicity, International Journal of Rock Mechanics and Mining Sciences, 34(2), pp. 249-261. DOI:10.1016/s0148-9062(96)00039-3.

[6] Potyondy, D.O., and Cundall, P.A., (2004). A Bonded-Particle Model for Rock, International Journal of Rock Mechanics and Mining Sciences 41(8), pp. 1329-1364. DOI:10.1016/j.ijrmms.2004.09.011.

[7] Rannou, J., Limodin, N., Réthoré, J., Gravouil, A., Ludwig, W., Baïetto-Dubourg, M.-C., Buffière, J.-Y., Combescure, A., Hild, F. and Roux, S. (2010). Three Dimensional Experimental and Numerical Multiscale Analysis of a Fatigue Crack, Computer Methods in Applied Mechanics and Engineering, 199(21), pp. 1307-1325. DOI: 10.1016/j.cma.2009.09.013.

[8] Guohua, C., and Linjie, C. (2013). Dynamic Fracture Research Based on XFEM and Its Application on Discharge Valve Guard of Hydrogen Compressor, Engineering Failure Analysis, 34(1), pp. 59-68.

DOI:10.1016/j.engfailanal.2013.07.002.

[9] Li, H., and Yuen Wong, L. N. (2012). Influence of Flaw Inclination Angle and Loading Condition on Crack Initiation and Propagation, International Journal of Solids and Structures, 49(18), pp. 2482-2499. DOI:10.1016/j.ijsolstr.2012.05.012.

[10] Abaqus/ CAE (2017) user s manual 6.10, product of Dassault systems simulia corp., providence.

[11] Giner, E., Sukumar, N., Tarancón, J.E. and Fuenmayor, F.J. (2009). An Abaqus Implementation of the Extended Finite Element Method, Engineering Fracture Mechanics, 76(3), pp. 347-368.

DOI:10.1016/j.engfracmech.2008.10.015.

[12] Grégoire, D., Maigre, H., Réthoré, J. and Combescure, A. (2007). Dynamic Crack Propagation Under MixedMode Loading - Comparison Between Experiments and X-FEM Simulations, International Journal of Solids and Structures, 44(20), pp. 6517-6534. DOI:10.1016/j.ijsolstr.2007.02.044.

[13] Mohammadi, Soheil, ed., (2008). Extended Finite Element Method, DOI:10.1002/9780470697795.

[14] Zamani, A., and Eslami, M. R. (2010). Implementation of the Extended Finite Element Method for Dynamic Thermoelastic Fracture Initiation, International Journal of Solids and Structures, 47(10), pp. 1392-1404. DOI:10.1016/j.ijsolstr.2010.01.024.

[15] Abrate, Serge, ed. (2011). Impact Engineering of Composite Structures, CISM International Centre for Mechanical Sciences, DOI:10.1007/978-3-7091-0523-8.

[16] Kuruppu, M. D., Obara, Y., Ayatollahi, M. R., Chong, K. P. and Funatsu, T. (2013). ISRM-Suggested Method for Determining the Mode I Static Fracture Toughness Using Semi-Circular Bend Specimen, The ISRM Suggested Methods for Rock Characterization, Testing and Monitoring, pp. 107-114. DOI:10.1007/978-3-319-07713-0_8.

[17] Iqbal, M. J., and Mohanty, B. (2006). Experimental Calibration of ISRM Suggested Fracture Toughness Measurement Techniques in Selected Brittle Rocks, Rock Mechanics and Rock Engineering, 40(5), pp. 453-475. DOI:10.1007/s00603-006-0107-6. 
[18] Zhou, Y.X., Xia, K., Li, X.B., Li, H.B., Ma, G.W., Zhao, J., Zhou, Z.L. and Dai, F. (2012). Suggested Methods for Determining the Dynamic Strength Parameters and Mode-I Fracture Toughness of Rock Materials, International Journal of Rock Mechanics and Mining Sciences, 49, pp. 105-112. DOI:10.1016/j.ijrmms.2011.10.004.

[19] Chen, R., Xia, K., Dai, F., Lu, F. and Luo, S.N. (2009). Determination of Dynamic Fracture Parameters Using a Semi-Circular Bend Technique in Split Hopkinson Pressure Bar Testing, Engineering Fracture Mechanics, 76(9), pp. 1268-1276. DOI:10.1016/j.engfracmech.2009.02.001.

[20] Dai, F., Chen, R., Iqbal, M.J. and Xia, K. (2010). Dynamic Cracked Chevron Notched Brazilian Disc Method for Measuring Rock Fracture Parameters, International Journal of Rock Mechanics and Mining Sciences, 47(4) pp. 606-613. DOI:10.1016/j.ijrmms.2010.04.002.

[21] Dai, F., Xia, K., Zheng, H. and Wang, Y.X. (2011). Determination of Dynamic Rock Mode-I Fracture Parameters Using Cracked Chevron Notched Semi-Circular Bend Specimen, Engineering Fracture Mechanics, 78(15), pp. 2633-2644. DOI:10.1016/j.engfracmech.2011.06.022.

[22] Saouma, V.E., and Zatz I.J. (1984). An Automated Finite Element Procedure for Fatigue Crack Propagation Analyses, Engineering Fracture Mechanics, 20(2), pp. 321-333. DOI:10.1016/0013-7944(84)90137-1. 